\title{
Management Strategies and Maternal Outcome of Placenta Accreta
}

\author{
FERDOUSI CHOWDHURY ${ }^{1}$, MAHBUBAAKHTER ${ }^{2}$, ROKEYAKHATOON ${ }^{3}$, MORZINA BEGUM ${ }^{4}$, \\ MAHBUBA SIDDIQUA ${ }^{5}$, SAIDA AKTER ${ }^{6}$, RAHAT AFZA CHOWDHURY ${ }^{7}$ ANOARA BEGUM $^{8}$
}

\begin{abstract}
:
Objectives: To find out the proportion and maternal outcome of placenta accreta.

Materials and Methods: Total 10579 deliveries were served during January 2013 to $31^{\text {st }}$ December 2013 in the Department of Obstetrics and Gynecology of Addin Women Medical College Hospital, Dhaka. All patients who needed postpartum or cesarean hysterectomy for postpartum hemorrhage and diagnosed as placenta accreta after postpartum hysterectomy were included for the study. Among them who were antentally diagnosed as placenta previa with having other risk factors of placenta accreta, were evaluated by Doppler Sonography. All these cases such as diagnosed, suspected or only had multiple risk factors of placenta accreta were managed by a team approach and proper counseling of the patient's guardian about need of massive transfusion, hysterectomy, Intensive Care Unit (ICU) admission .

Results: Among the total 10579 deliveries 22 cases were diagnosed as placenta accreta after postpartum hysterectomy. On histopathology 8 of these cases were placenta percreta, 7 cases were placenta increta and 7 cases were placenta accreta vera. Almost ninety one (90.90\%) patient had placenta previa and $90.90 \%$ patient had past $\mathrm{H} / \mathrm{O}$ one or two cesarean section. Placenta percreta cases were more common in patients with $\mathrm{H} / \mathrm{O}$ two previous $\mathrm{C} / \mathrm{S}$ or one C/S and dilatation \& curettage (D\&C). In all preoperatively diagnosed cases, Right lower paramedian incision was given and hysterectomy was done leaving the placenta in situ.

Conclusion: Placenta accreta is associated with previous two or more cesarean deliveries, or multigravidae with past $H / O$ repeated $D \& C$ or M/R or combined. History of of these operations are diagnosed as having anterior or central placenta previa.
\end{abstract}

\section{Introduction:}

Placenta accreta is the severe form of obstetric complication, in which placenta is abnormally attached to the uterus. Once a rare occurrence, placenta accreta is becoming an increasingly common complication of pregnancy, likely related to the increasing rate of cesarean delivery over the last five decades $^{1,2}$. The incidence had increased from 1 in 4027 pregnancies in1970s, to 1 in 2510 pregnancies in the1980s s $^{3,4}$ and to 1 in 533 pregnancies for the period of $1982-2002^{5}$. Placenta accreta accounts for $7 \%$ $10 \%$ of maternal mortality ${ }^{6,7}$ and is currently the most common indication for peripartum hysterectomy ${ }^{8}$.

Although exact pathogenesis is unknown, an area of accretion of chorionic villi in direct contact with the myometrium and absence of decidua was found on hysterectomy specimen ${ }^{9,10}$. This decidual maldevelopment is usually associated with previous instrumentation as in the case of prior cesarean sections or uterine curratages ${ }^{11}$.

1. Ferdousi Chowdhury, Associate professor, Obstetrics \& Gynecology, Addin Women Medical College Hospital $(\mathrm{AWMCH})$, Dhaka.

2. Mahbuba Akhter, Asst. Professor, Obstetrics \& Gynecology AWMCH, Dhaka.

3. Rokeya Khatoon, Asst. Professor, Obstetrics \& Gynecology, AWMCH, Dhaka.

4. Morzina Begum, Asst. Professor, Obstetrics \& Gynecology, AWMCH, Dhaka.

5. Mahbuba Siddiqua, Asst. Professor, Obstetrics \& Gynecology, AWMCH, Dhaka.

6. Saida Akter, Asst. Professor, Obstetrics \& Gynecology, AWMCH, Dhaka.

7. Rahat Afza Chowdhury, Asst. Professor, Obstetrics \& Gynecology, AWMCH, Dhaka.

8. Anoara Begum, Professor, Obstetrics \& Gynecology, AWMCH, Dhaka. 
It is important to diagnose placenta accreta prior to delivery, as early in the pregnancy as possible, in order to allow prevention of maternal mortality and morbidity due to massive hemorrhage ${ }^{12}$. Wong et al. reported that sonographic findings performed with gray-scale and Doppler ultrasonography had $89 \%$ sensitivity and $98 \%$ specificity for the diagnosis of placenta accreta ${ }^{13}$.

Delivery plan requires multidisciplinary team approach, which should involve an anesthesiologist, Obstetrician, pelvic surgeon such as gynecologic oncologist, intensivist, maternal -fetal medicine specialist, neonatologist, urologist, hematologist and interventional radiologist to optimize patient's outcome $^{14,15}$. Patient counseling include discussion of potential need of hysterectomy, the risks of profuse hemorrhage and possible maternal death. Generally recommended management of placenta accreta is preterm cesarean hysterectomy with the placenta left in situ. An alternative approach to preserve the uterus, leaving the placenta in situ, has been reported. However, this approach should be considered only when patient has a strong desire for future fertility as well as hemodynamic stability, normal coagulation status, and is willing to accept the risks involved in the conservative approach ${ }^{14}$.

\section{Methodology:}

This study was conducted in Addin Women Medical College Hospital during the period of $1^{\text {st }}$ January 2013 to $31^{\text {st }}$ December 2013. Total 10579 deliveries occurred during the study period; 24 cases of postabortion and postpartum hysterectomy were done. Among them 22 cases were diagnosed cases of placenta accreta following cesarean hysterectomy and included for the study, 17 cases were antenatally diagnosed as placenta praevia with previous $\mathrm{H} / \mathrm{O}$ cesarean section and or D\&C. These cases were reevaluated by Doppler Ultrasonography for invasiveness of placenta. After diagnosis of placenta accreta, patient's guardian were counseled about need of cesarean hysterectomy, massive blood transfusion, ICU admission and even death. Urologist and anaesthesiologist were also consulted before hysterectomy. Other 5 cases were diagnosed peroperatively. One of these 5 cases was diagnosed during D\&C for 12 weeks missed abortion.

The following relevant data were recorded: maternal age, parity, gestational age, previous cesarean deliveries and $D \& C$, past $H / O$ abortion and $M / R$, presence of placenta praevia, placenta accreta and degree of invasiveness.
During management of these cases surgical intervention, estimated amount blood loss, amount of blood transfusion bags, need of ICU admission and length of hospital stay were noted.

\section{Results:}

Total 10579 deliveries occurred during the study period. 24 patients needed post partum hysterectomy for clinical placenta percreta and uncontrolled postpartum hemorrhage. Among them 22 cases were histologically diagnosed as placenta accreta, giving rise to proportion of 1 in 481 deliveries.

Maternal demographic characteristics, risk factors for placenta accreta, clinical assesment in terms of blood and amount of blood transfusion in relation to placenta accreta are shown in table I,II and III.

According to histopathological classification, 8 patient had placenta percreta, 7 had placenta increta and 7 had placenta accreta vera.

Only one patient had placenta percreta in first trimester (12 weeks), all other cases were in 27 to 41 weeks gestational age of pregnancy.

$20(90.90 \%)$ patient had placenta praevia type II anterior, type III anterior and central type. These 20 patient also had previous $\mathrm{H} / \mathrm{O}$ cesarean section.

Ten (45.45\%) patients had past $\mathrm{H} / \mathrm{O}$ of abortion, M/R and dilatation and currettage. Seven patients had $\mathrm{H} /$ O prior D\&C operation they were grand multigravidae.

Placenta accreta cases were,more commonly associated with previous $\mathrm{H} / \mathrm{O}$ two cesarean section or one cesarean section and H/O D\&C. Two cases of placenta praevia patient came with intrabdominal hemorrhage due to spontaneous perforation of placenta in third trimester.

In 3 cases of central placenta praevia, placenta invaded broad ligament and bladder. These were very much difficult cases and huge bleeding occurred.

During management of the antenatally diagnosed cases, right lower paramedian incision was given. Baby was delivered by high transverse incision in the upper segment and placenta was left unseparated. Subtotal hysterectomy was done in 5 cases of type II anterior placenta praevia. Total hysterectomy in 5 cases and supracervical hysterectomy was done in other cases.

One of the case of placenta percreta invading bladder and parametrium, needed intrabdominal condom 
tamponade for 24 hours after cesarean hysterectomy, to prevent continuous oozing of blood from bladder and surrounding tissues.

In another two cases of placenta percreta Descending cervical and vaginal branch of uterine artery of both side were ligated per vaginally at the level of the cervicovaginal junction, to prevent bleeding from cervicovaginal junction and bladder base even after hysterectomy.

Even another one case required codom tamponade from below, between posteroinferior surface of the bladder and posterior part of lower segment of uterus. Because anterior part of lower segment was totally replaced by placental tissue.

Bladder was opened up in 3 cases pf placenta percreta.

Two patients were shifted to ICU. One of them died after 24 Hours.

Table-I

Placenta Accreta in relation to maternal characteristics (n-22)

\begin{tabular}{lcc}
\hline Characteristics & Mean & Range \\
\hline Age in years & 27.9 & $20-38$ \\
Gravidity & 3.38 & $2-5$ \\
Parity & 1.66 & $1-3$ \\
Gestational age in weeks & $36.2^{*}$ & $27-41$ \\
\hline
\end{tabular}

* One patient had 12 weeks pregnancy

Table-II

Risk Factors of Placenta Accreta (n-22)

\begin{tabular}{lcc}
\hline Risk factors & No. of patients & Percentage \\
\hline Prior cesarean section & 20 & 90.90 \\
$\begin{array}{l}\text { Prior dilatation and } \\
\text { curettage operation }\end{array}$ & 7 & 31.81 \\
Past H/O abortion,M/R & 10 & 45.45 \\
\hline
\end{tabular}

Table-III

Clinical parameters in relation to cesarean hysterectomy (n-22)

\begin{tabular}{lcc}
\hline Characteristics & Mean & Range \\
\hline Estimated blood loss in liters & 2.55 & $2-7$ \\
Blood transfusion units & 5.45 & $2-12$ \\
Postoperative stay in hospital in days & $8.3^{*}$ & $8-22$ \\
\hline
\end{tabular}

${ }^{*}$ A patient who died in ICU excluded

\section{Discussion:}

The incidence of placenta accrete has risen in parallel with that of cesarean section and will remain a major cause of maternal morbidity and mortality as the principle indication of postpartum hysterectomy with excessive blood loss ${ }^{16,17,18}$. In our Hospital, during the study period the principle cause of postpartum hysterectomy was placenta accreta(95.65\%).

Placenta accreta occurs approximately 1 in 1000 deliveries with a reported range from $.04 \%$ to $.9 \% 5,4,19$. Differences in definition and study population may account for this wide range.

The proportion of placenta accreta was 1/481 deliveries in our centre. This incidence is nearer to the incidence $(1 / 426)$ found in a retrospective study done by Evsen et $\mathrm{al}^{20}$, at (centre A) of Dicle University Hospital, Turkey. But this is little higher than the incidence 1 in 695 deliveries reported by Nargis Iqba| ${ }^{21}$ in a study done in Jinnah Hospital, Lahore, Pakistan.

Ayesha $A$ rif $^{22}$ reported an incidence of 1 in 131 deliveries in Pakistan Armed Forces Medical Hospital.

In this study it was revealed that multi gravidity due to abortion, $M / R$ was more related to placenta accreta than multi parity. 12(\%) patient were primipara but 6 of them had gravity more than two due to previous abortion or M/R. $77.27 \%$ patient were multigravidae and $22.73 \%$ were grand multigravidae which is similar to other studies $22,23,24,25$.

Women at greatest risk of placenta accreta are those who have myometrial damage caused by a previous cesarean delivery with either anterior or posterior placenta praevia overlying the uterine scar ${ }^{14}$. In this study previous $\mathrm{H} / \mathrm{O}$ cesarean section was present in $90.91 \%$ cases and placecnta previa was also present in $90.91 \%$ cases. Sadia Jalil 24 reported $93 \%$ of placenta previa with placenta accreta in their study.

$\mathrm{H} / \mathrm{O}$ dilatation and curettage was present in $18.18 \%$ cases. This is also similar to other studies 22,23 .

Maternal death has been reported up to $7 \%$ cases $^{6}$. Mortality and morbidity is associated with undiagnosed and unplanned managed cases. In the present study a patient delivered a dead fetus, and after severe post partum hemorrhage, hysterectomy was done and diagnosed as a case of placenta percreta. After hysterectomy patient was shifted to ICU and she died after 24 hours. So to prevent this catastrophic situation antenatal diagnosis and multidisciplinary approach are necessary. 


\section{Conclusion:}

Woman who had previous two or more cesarean deliveries, or multigravidae with past $\mathrm{H} / \mathrm{O}$ repeated $D \& C$ or $M / R$ or combined $\mathrm{H} / \mathrm{O}$ of these operations diagnosed as having anterior or central placenta previa managed after detailed sonographic screening and evaluation for placenta accreeta results good outcome.

\section{References:}

1. B. E. Hamilton, J. A. Martin, S. J. Ventura, P. D. Sutton, and F. Menacker, "Births: preliminary data for 2004," National vital Statistics Reports, 2005; 54,(8), 1-17.

2. Silver RM,Landon MB, Rouse DJ, Leveno KJ, Spong CY, Thom EA, et al, Maternal morbidity associated with repeat multiple cesarean deliveries. National Institute of and Child Health and Human Development Maternal- Fetal Medicine Units Network. Obstet Gynecol 2006; 107: 1226-32.

3. Read JA, Cotton DB, Miller FC. Placenta accreta: changing clinical aspects and outcome. Obstet Gynecol 1980;56:31-4.

4. Miller DA, Chollet JA, GoodAwin TM. Clinical risk factors for placenta previa-placenta accreta. Am J Obstet Gynecol 1997;177:210-4.

5. Wu S, Kocherginsky M, Hibbard JU. Abnormal placentation: twenty-year analysis. Am J Obstet Gynecol 2005;192: 1458-61.

6. O'Brien JM, Barton JR, Donaldson ES. The management of placenta percreta: conservative and operative strategies. Am J Obstet Gynecol 1996;175: 1632-8.

7. 7.Chandraharan E, Rao S, Belli AM, Arulkumaran $S$, The Triple-P procedure as a conservative surgical alternative to peripartum hysterectomy for placenta accreta. Int J Gynaecol Obstet. 2012; 117(2): 191-194

8. Chitra Sivasankar,Perioprative management of undiagnosed placenta percreta: A case report and management strategies, Int J Womens Health. 2012; 4: 451-454.

9. P. Tantbirojn, C. P. Crum, and M. M. Parast, "Pathophysiology of placenta acreta: the role of decidua and extravillous trophoblast," Placenta. 2008; 29 (7): 639-645.
10. F. Alkazaleh, M. Geary, J. Kingdom, J. R. Kachura, and R. Windrim, "Elective non-removal of the placenta and prophylactic uterine artery embolization postpartum as a diagnostic imaging approach for the management of placenta percreta: a case report," Journal of Obstetrics and Gynaecology Canada. 2004; 26 (8) : 743-746.

11. K. Benirschke, P. Kaufmann, and R. N. Baergen, Pathology of the Human Placenta, 2006; 5th edition, Springer, New York, NY, USA.

12. J.-J. Tseng and M.-M. Chou, "Differential expression of growth-, angiogenesis- and invasion-related factors in the development of placenta accreta," Taiwanese Journal of Obstetrics and Gynecology. 2006; 45(2): 100-106.

13. Sherer DM, Gorelick C, Zigalo A, Sclfani S, Zinn $\mathrm{HL}$, Abulafia O, Placenta previa percreta managed conservatively with methotrexate and multiple bilateral uterine artery embolizations, Ultrasound Obstet Gynaecol 2007; 30: 227-228.

14. H. S. Wong, K. C. Ying, J. Zuccollo, J. Tait, and K. C. Pringle, "Evaluation of sonographic diagnostic criteria for placenta accreta," Journal of Clinical Ultrasound. 2008; 36 (9): 551-559.

15. "ACOG committee opinion. Placenta accreta. Committee on Obstetric Practice American College of Obstetricians and Gynecologists. JULY 2012; 529.

16. 16.C. R. Warshak, G. A. Ramos, R. Eskander et al., "Effect of predelivery diagnosis in 99 consecutive cases of placenta accreta," Obstetrics and Gynecology. 2010; 115 (1): 65-69.

17. 17.Eller AG, Bennett MA, Sharshiner M,et al. Maternal morbidity in cases of placenta accreta managed by a multidisciplinary care team compared with standard obstet care. Obstet Gynecol 2011;117: 331-337.

18. Eller AG, Porter TF, Soisson P, Silver RM. Optimal management strategies for placenta accreta. BJOG 2009; 116: 648-54.

19. 19. Briery $\mathrm{CM}$, Rose $\mathrm{CH}$, Hudson WT, et al. Planned vs emergent cesarean hysterectomy. Am J Obstet Gyne col 2007;197: 154-159. 
20. 20. S. L. Clark, P. P. Koonings, and J. P. Phelan, "Placenta previa/accreta and prior cesarean section," Obstetrics and Gynecology, 1985; 66(1): 89-92.

21. Evsen MS, Sak ME, Soydine HE, Nur CF, Mehmet O,Gul .Retrospective analysis of placenta accreta: management strategiesevaluation of 41 cases.Ginekol Pol. 2012; 83(7):501-4.

22. Iqbal N, Sohail N, Tayyab M, Placenta Accreta Still a Dilemma, ANNALS 2012;18(3): 250-254.
23. Arif A. Study of frequency and outcome of management in pregnancies complicated by Morbid adherence of placenta.PakArmed Forces Med Journal 2010; 4(12): 131-136.

24. Jalil S, Nausheen S, Akhtar A Z, Reducing morbidity and mortality in morbidly adherent placenta: an experience Pak J Surg 2011; 27(1): 59-63.

25. Gielchinsky Y, Mankuta D, Rojansky N, et al. Perinatal outcome of pregnancies complicated by placenta accreta. Obstet Gynecol 2004; 104: 527-530. 